Research Article

\title{
Two-Dimensional Parametric Study of an Embankment on Clay Improved by an Artificial Crust Composite Foundation
}

\author{
Ying Wang, ${ }^{1,2}$ Zhenhua Hu (D, ${ }^{1}$ Yonghui Chen, ${ }^{2}$ and Hongtian Xiao ${ }^{1}$ \\ ${ }^{1}$ Shandong Key Laboratory of Civil Engineering Disaster Prevention and Mitigation, \\ Shandong University of Science and Technology, Qingdao 266590, China \\ ${ }^{2}$ Key Laboratory of Ministry of Education for Geomechanics and Embankment Engineering, Hohai University, \\ Nanjing 210098, China \\ Correspondence should be addressed to Zhenhua Hu; skd994409@sdust.edu.cn
}

Received 21 April 2020; Revised 24 July 2020; Accepted 5 August 2020; Published 24 August 2020

Academic Editor: Jia-wen Zhou

Copyright (๑ 2020 Ying Wang et al. This is an open access article distributed under the Creative Commons Attribution License, which permits unrestricted use, distribution, and reproduction in any medium, provided the original work is properly cited.

\begin{abstract}
In order to reduce the foundation settlement, conserve resources, and be environmental-friendly while increasing the use of soil resources, an artificial crust layer formed by in situ stabilization is proposed to combine with prestressed pipe piles over soft ground in road construction. In this study, a centrifuge test and two-dimensional coupled-consolidation finite-element analyses are conducted to simulate the construction of an embankment. And a two-dimensional parametric study is conducted to study the performance indicated by maximum long-term settlement, excess pore water, and tensile stress under various conditions. The results of the centrifuge test clearly show that the measured settlement, excess pore water, and tensile stress are in good agreement with the calculated results. In addition, the key factors of pile spacing and thickness and strength of the crust have an influence on the maximum settlement, stress of the foundation, and tensile stress of the crust using the two-dimensional coupled-consolidation finite-element analyses. And the stress transfer regular of the foundation is analyzed under various conditions. Moreover, the failure of the crust contained tensile cracking and shearing failure and the thickness of the pile that pierced the crust are also affected by the key factors.
\end{abstract}

\section{Introduction}

Settlement of the building and slope stability accidents are induced by the construction of an embankment. Obviously, it is necessary to find an effective solution for treating soft soil. Technological improvements of the foundation have been developed with conserving resources, preventing environmental pollution, and increasing the use of soil resources. Specifically, it has been proposed to combine prestressed pipe piles with an artificial crust layer formed by in situ stabilization over soft ground during road construction in order to reduce the settlement of foundation.

The technology is called artificial crust composite foundation or crust composite foundation. The artificial crust, formed by in situ stabilization with a higher compressive modulus and cohesion, replaces the traditional sand cushion in pile-supported embankments, which reduces the total and differential settlement and improves the global stability of Earth structures on a deep soft soil layer. It is a common method to make the composite foundation with acceptable settlement so as to maintain the proper function of the high standard road or the embankments on the soft ground.

In order to conform to the engineering, the interaction between foundation-cushion-load under rigid composite foundation was studied by centrifugal model test. [1-3].

It is common to apply numerical simulation method to describe the characteristics of soil in the geotechnical engineering, and the results of numerical analysis compared with the field engineering or model test are effective depending on the suited constitutive model of soil materials. In addition, it is difficult to obtain accurate results of the analytical calculation owing to the limitation and complexity, so there is a vast literature on methods to solve the behavior of pile-supported embankments using the finiteelement method (FEM) [4-17]. The values of numerical 
simulation method were determined based on the experiment [18-21]. Plane-strain models are usually adopted in analyzing the behavior of embankments on soft soil based on the FEM, while the columns are usually modeled as $1 \mathrm{~m}$ continuous walls in a column-improved (including a pileimproved) deposit $[22,23]$. The results of lateral displacement and bending moment in the columns were incorrect in the two-dimensional (2D) analysis under the toe of the embankment by Chai et al. [23]. However, the results of the settlement of the foundation and the excess pore pressure match well with the results of the field-measured results using a $2 \mathrm{D}$ model. Based on these studies, the maximum long-term settlement and excess pore pressure could be analysed by using the $2 \mathrm{D}$ FE model.

The work of a combined foundation improvement technology in this area is ongoing and varied. For example, Jelisic and Leppänen [24] proposed the organic soft soil treated by stabilization combined with lime piles; another important constraint on all the work discussed in this area is that no theoretical method exists. The primary method that has been used in the literature $[25,26]$ is a new method to predict the total settlement for a method combining stabilization and a floating-type deep cement mixing of the soil stabilization method based on several loading model tests. As far as we know, there is no definite research on the behavior study of an artificial crust combined with rigid piles. So, in this study, a centrifuge test and two-dimensional coupled-consolidation finite-element analyses were conducted to simulate the construction of an embankment for stabilization combined with rigid piles. Based on the twodimensional coupled-consolidation finite-element models, the impact of several key factors, including pile spacing, thickness, and strength of the crust on the maximum longterm settlement, excess pore water, and tensile stress are discussed. Finally, the influences of these factors are compared and evaluated according to their importance.

\section{Centrifuge Model Testing}

The centrifuge model tests were adopted in this paper. The centrifuge model tests were performed at the Geotechnical Centrifuge Facility of Hong Kong University of Science and Technology [27]. The main purpose of the centrifuge model tests is analyzing the stress and deformation in the crust composition foundation. The centrifuge test was performed at a centrifugal acceleration of $80 \mathrm{~g}$ (g denotes the Earth's gravity) and completed in one flight. The plane dimension of the model box was $600 \mathrm{~mm} \times 100 \mathrm{~mm} \times 310 \mathrm{~mm}$ (i.e., $48 \mathrm{~m} \times 8 \mathrm{~m} \times 24.8 \mathrm{~m}$ in the prototype), the height of the embankment was $56.3 \mathrm{~mm}$ (i.e., $4.5 \mathrm{~m}$ in the prototype), the length of the piles was $200 \mathrm{~mm}$ (i.e., $16 \mathrm{~m}$ in the prototype), the pile spacing was $37.5 \mathrm{~mm}$ (i.e., $3.0 \mathrm{~m}$ in the prototype), and the crust was with a thickness of $21 \mathrm{~mm}$ (i.e., $1.68 \mathrm{~m}$ in the prototype), which are shown in Figure 1. Yao et al. [28] had discussed the boundary effect of the side friction in the centrifugal tests. The distance from the box edges was approximately $100 \mathrm{~mm}$, while, in the paper, the distance from the foot of the embankment to the box boundary was $100 \mathrm{~mm}$.
A digital camera was mounted at $450 \mathrm{~mm}$ at the front of the transparent sidewall, with a maximum resolution of $2592 \times 1944$ pixels to capture digital images of the soil at various stages during the in-flight test. Processing two subsequent digital images quantified the movement of the soil. The movement of the soil was corrected by particle image velocimetry (PIV) analysis coupled with a close-range photogrammetry [29].

Model material and centrifuge modeling procedure were described in detail by Wang et al. [30, 31]. In this study, pore water pressure sensors and strain gauges were used, in addition to measuring soil and pile motion. In addition, strain gauges were installed at the bottom of the crust, which are shown in Figure 1. The pore water pressure transducers were installed underneath each embankment, which were adjacent to the middle pile to confirm the time effect at depths of $31.3 \mathrm{~mm}$ (i.e., $2.5 \mathrm{~m}$ in the prototype) from the surface of the ground.

The centrifuge model test was conducted to study the load responses and deformation in the crust composite foundation. In addition, the deformation characteristics of the crust were also investigated. Based on the investigations, the following conclusions can be drawn.

By the deformation, it was found that the final middle settlement of the crust composite foundation can be reduced. The excess pore water pressure is lower during the loading period and the dissipation rate of the excess pore water pressure is slower at the same loading period. The explanation for this event is that the stress can be spread and reduced due to the crust with the properties of plate. Thus, the consolidation rate became slower based on the low permeability of the crust.

By comparing the axial force of the piles, the axial force of the middle pile is smaller. However, the axial force of side pile is higher in the crust composite foundation. This can be explained by the following observations: the redistribution of foundation stress by the crust with the properties of plate, the fully functioning bearing capacity of the side section, and the conflict between the crust and the subsoil. The largest tensile stress occurred in the middle of the crust and the characteristics of a similar plate were taken to depend on the tensile stress changing, as well as on the maximum tensile stress occurring at the end of the construction. In conclusion, cracking damage of the crust occurred during the loading period.

\section{Finite-Element Analysis}

3.1. Modeling. The centrifuge tests were backanalyzed to promote a better understanding of the centrifuge tests and calibrate a constitutive model and its model parameters against the measured data.

The piles are usually modeled as continuous walls by the two-dimensional coupled-consolidation analyses, using the finite-element program PLAXIS 2D (Hohai University 2017, Code: CP12111492f4498588b0).

Due to symmetry, only half of the finite-element model and the boundary conditions were modeled, as shown in Figure 2. The modeled area had a vertical thickness of $19.9 \mathrm{~m}$ 


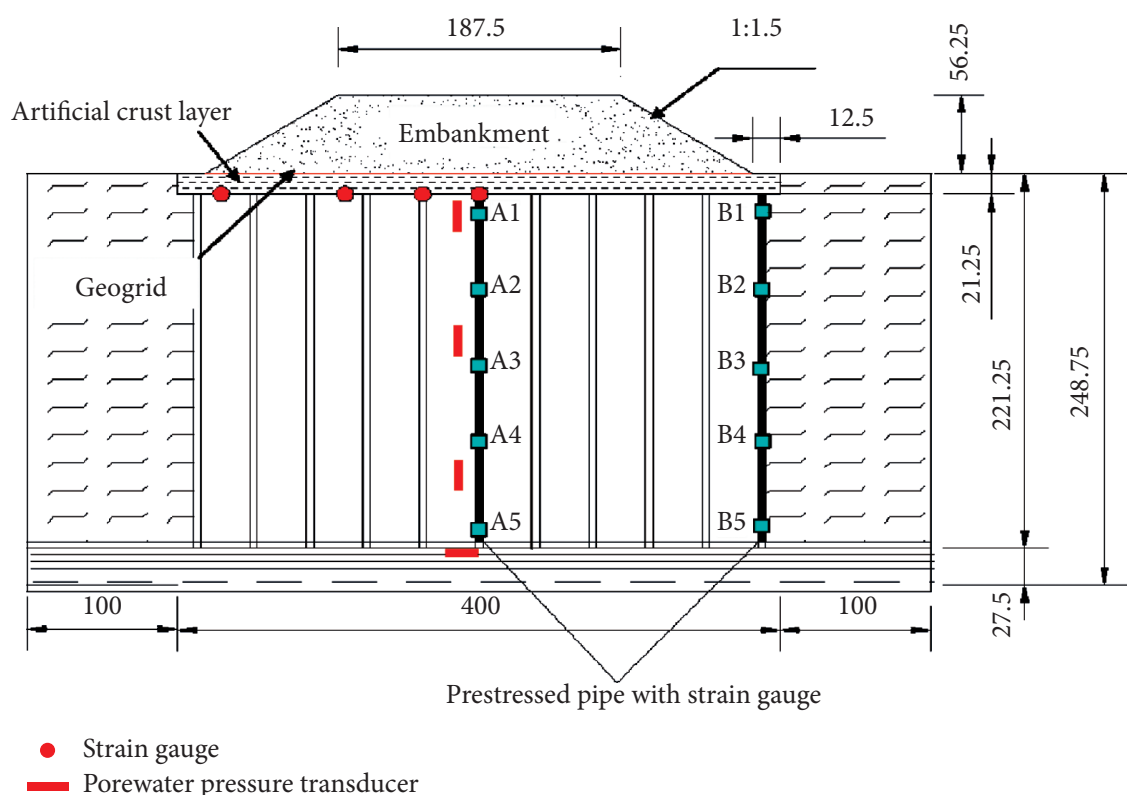

(a)

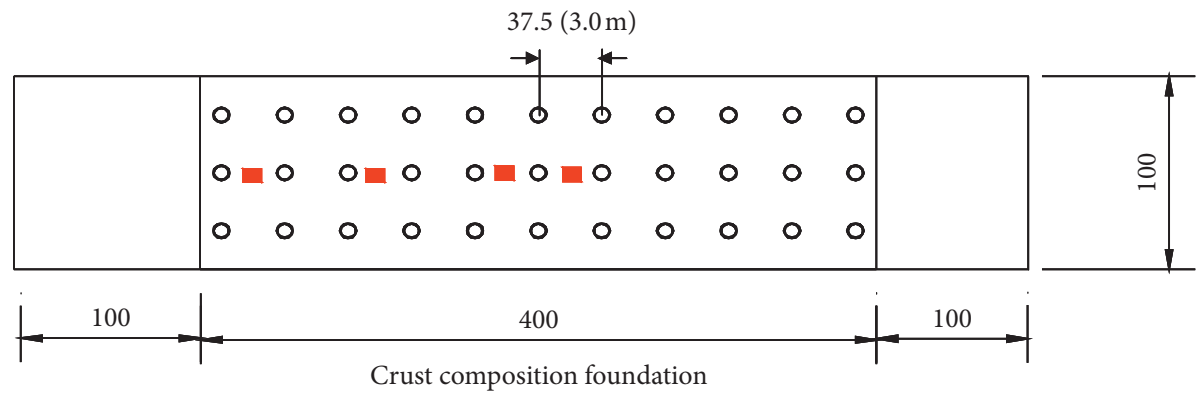

(b)

FIGURE 1: Schematic view and arrangement of a typical test model under (g) (unit: mm). (a) Crust composite foundation. (b) A plane diagram.

from the ground surface and an overall horizontal width of $24 \mathrm{~m}$. The soil and artificial crust domains were represented by 15 -node triangular elements and the geosynthetic layer was represented by 5 -node geogrid elements. The pile is calculated by plate element. Slippage between the soil and the piles was modeled by interface elements. McDowell et al. [32] assumed $0.1 \mathrm{~m}$ thickness of the annulus. The bottom boundary displacements of the mesh were set to zero. All the degrees of freedom were constrained except for the vertical movement.

The effective unit weight of filling below the groundwater level was changed due to the effect of buoyancy; when the filling was settled into the groundwater with the loading, the effective unit weight decreased under the groundwater level. The update grid and water pressure were adopted in this finite-element program.

\subsection{Conversion of Three-Dimensional Problem into Two-Di-} mensional Plane-Strain Model. A three-dimensional model with a square column configuration can be simplified into a two-dimensional plane-strain model in the equivalent area method [33] as follows:

$$
D_{p}^{\prime}=\frac{\pi D_{p}^{2}}{4 d},
$$

where $D_{p}^{\prime}$ is the width of the equivalent pile wall; $D_{p}$ is the diameter of the isolated pile; and $d$ is the center-to-center distance in the direction perpendicular to the plane of the embankment's cross section. However, the three-dimensional character of the panel geometry cannot completely be replaced by the equivalent area method. Therefore, the equivalent properties approach for the panels was adopted $[5,34,35]$.

The equivalent properties for the panels were calculated based on the weighted average area while keeping the panel width the same as in the three-dimensional geometry based on the following equation:

$$
\begin{aligned}
& E_{\mathrm{eq}}=\frac{E_{p} A_{p}+E_{s} A_{s}}{A_{p}+A_{s}}, \\
& E_{\mathrm{eq}}=\frac{\pi D_{p}}{4 d} E_{p}+\left(1-\frac{\pi D_{p}}{4 d}\right) E_{s},
\end{aligned}
$$




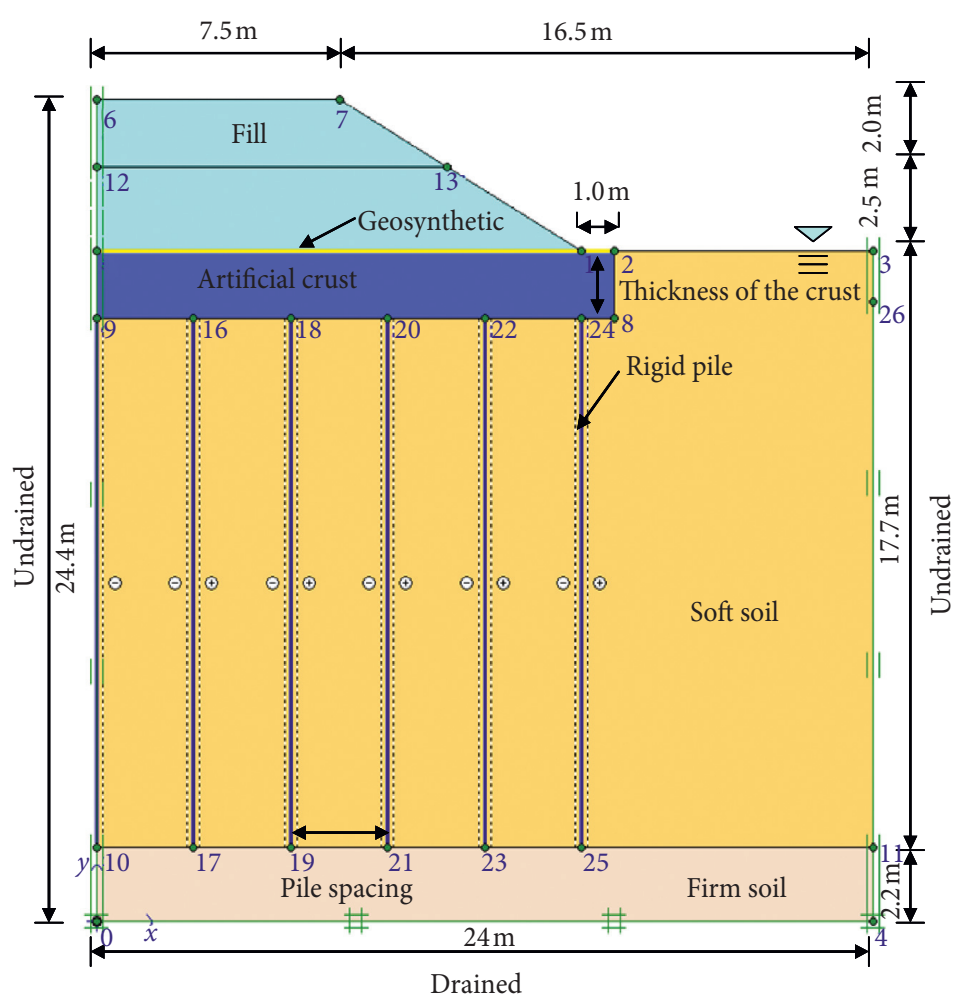

FIgUre 2: The 2D FE geometry model.

where $E_{p}$ is the elastic modulus of the pile; $E_{s}$ is the elastic modulus of the soil; $A_{p}$ is the sectional area of the pile; $A_{s}$ is the sectional area of the soil; $E_{\mathrm{eq}}$ is the equivalent elastic modulus of the panels.

3.3. Constitutive Models and Parameters. The embankment fill was modeled as an elastic-perfectly plastic material using the Mohr-Coulomb (MC) model. The firm clay at the bottom and the soft clay layers were modeled as the elasticperfectly plastic materials using the Modified Cam-Clay (MCC) model. The material properties of the embankment fill and the soil layers are presented in Table 1. In this table, the values were determined based on experiment. In addition, $E A=1 * 10^{5} \mathrm{KN} / \mathrm{m}$ was adopted for the geogrid. Apart from these, the model pile was modeled as a linear elastic material. The elastic modulus of model pile was set $38 \mathrm{GPa}$, and the width of the equivalent pile wall and the equivalent elastic modulus of the panels were calculated by equations (1) and (2), and Poisson's ratio was set as 0.15 .

Based on the hydraulic conductivity method by Chai et al. [23], the values of $k_{v}$ were estimated as twice the values of incremental loading consolidation tests deduced from the laboratory. The values of the horizontal hydraulic conductivity, $k_{h}$, were set as 1.5 times the corresponding value of $k_{v}$, based on the previous experiences.

The values of $k_{v}$ listed in Table 1 are initial values and, during consolidation, they were allowed to vary with the void ratio according to the following equation:

$$
k=k_{0} \times 10^{\left(-\left(e_{0}-e\right) / c_{k}\right)},
$$

where $k_{0}=$ initial hydraulic conductivity, $e_{0}=$ initial void ratio, $k=$ current hydraulic conductivity, $e=$ current void ratio, and $c_{k}=$ a constant, which was, in this study, assumed as $c_{k}=0.5 e_{0}$.

A permeability coefficient for cement treated soil in the paper was $1 * 10^{-9}$.

The formation method for the artificial crust was the same as that for the Deep Cement Mixing DCM columns. Therefore, the material properties of the crust are dependent on the DCM columns. In the 2D FE model, the artificial crust was modeled as a linear elastic material and only the elastic modulus of the crust was used. After an extensive literature review, Filz and Navin [4] proposed that the elastic modulus of DCM columns should be in the range of $50 q_{u}-250 q_{u}$ when the DCM columns are constructed by a dry mixing method. The values of $q_{u}$ were obtained from the laboratory unconfined compression test. Bruce [36] and Porbaha et al. [37] reported that the elastic modulus of DCM columns should be $100 q_{u}$. Furthermore, Yapage et al. [35] suggested that the correlation between the elastic modulus and the unconfined compression strength, $E=118 q_{u}$, was used for the cementstabilized soil.

So, $E=100-300 \mathrm{MPa}$ was determined based on the unconfined compression strength and chosen for the 2D FE model. And the Poisson ratio of artificial crust was set as 0.15 .

\section{Results and Discussion}

In this paper, interpretation of the results was only focused on the responses of the ground and pile due to the 
TABLe 1: Material properties of the embankment and subsoil.

\begin{tabular}{lccc}
\hline Parameter & Soft clay & Firm clay & Embankment fill \\
\hline Thickness $(\mathrm{m})$ & 17.7 & 2.2 & 4.5 \\
Material model & MCC & MCC & MC \\
Material type & Undrained & Undrained & 16.6 \\
Unit weight $\gamma\left(\mathrm{kN} / \mathrm{m}^{3}\right)$ & 15.2 & 18 & Drained \\
Saturated unit weight, $\gamma_{\text {sat }}\left(\mathrm{kN} / \mathrm{m}^{3}\right)$ & 18 & 0.63 & 20 \\
Coefficient of lateral Earth pressure, $K_{0}$ & 0.9 & 2.0 & - \\
Void ratio, $e_{0}$ & 1.59 & 0.121 & - \\
Slope of the isotropic normal compression line, $\lambda$ & 0.4 & 0.011 & - \\
Slope of the isotropic unload-reload line, $\kappa$ & 0.053 & 1.277 \\
Stress ratio, $M$ & 0.984 & - & - \\
Effective friction angle, $\varphi^{\prime}($ degrees $)$ & - & - & - \\
Effective cohesion, $c^{\prime}(\mathrm{kPa})$ & - & 0.25 & - \\
Poisson's ratio, $v$ & 0.3 & - & 0.1 \\
Dilatancy angle, $\Psi$ & - & - & 2 \\
Elastic modulus $E(\mathrm{MPa})$ & - & $8 \times 10^{-4}$ & 20 \\
Permeability $k_{v}(\mathrm{~cm} /$ day) & & $8 \times 10^{-3}$ & 1.0 \\
\hline
\end{tabular}

construction of the embankment. All results were presented in the prototype scale unless otherwise stated.

\subsection{Results and Comparisons}

4.1.1. Settlement. Usually, the settlement is one of the focus areas when an artificial crust composition foundation is used for supporting roadways, railways, etc. In the past, the settlement at the base of the embankment had been focused by most investigators because the long-term maximum settlement occurred at this location. However, the postconstruction settlement is actually a more direct indicator, and it is critical to the serviceability of the roads on the embankment [5]. In this study, the emphasis was placed on the postconstruction settlement and the maximum longterm settlement.

The settlement based on the centrifuge experiment and the settlement-time history in the center of the embankment are shown in Figure 3. In addition, Figure 3 also shows the comparison between the measured and computed settlement values at the base of the embankment using the finite-element model. The settlement close to the middle of the crust composite foundation measured at the end of the construction (300 days) was $18.0 \mathrm{~cm}$. On 2000 day, assumed to be close to the end of the settlement period, the maximum long-term settlement in the middle of the crust composite foundations was $27.4 \mathrm{~cm}$. The postconstruction settlement of the crust composite foundations was $9.4 \mathrm{~cm}$ in the prototype. This project requires the residual settlement of the embankment and the road surface to be less than $0.3 \mathrm{~m}$ at the completion of construction [23].

The measured maximum long-term settlement met the engineering requirements. The settlement was $25.4 \mathrm{~cm}$ at the end of the construction and the maximum long-term settlement in the middle of the crust composite foundations was $28.4 \mathrm{~cm}$ using the finite-element model. The computed long-term settlement values agreed well with the experimental measurements. Therefore, the influence of the key factors on the settlement was demonstrated using the finiteelement model.

4.1.2. Excess Pore Water Pressure. During the construction and traffic loading, excessive pore water pressure is generated within soft soil, which dissipates simultaneously in two ways: hydraulically and mechanically (i.e., drainage and load transfer to the piles) [38]. The former way refers to a portion of the excessive pore water pressure dissipates by drainage. The corresponding load is transferred to the soil skeleton, resulting in the increasing effective stress. Meanwhile, the latter way, mechanically, as the effective stress in the soil increases, the soil tends to settle more than the piles. A portion of the load will be transferred to the piles on stress within the embankment because of the relative movement between the soft soil and the piles. As a result, the excessive pore water pressure in the soft soil will be dissipated much faster than by drainage alone.

Traditional consolidation theories underestimate the degree of consolidation owing to the artificial crust in the artificial crust composition foundation.

In the study of the stress transfer and the consolidation rate of the subsoil, the most direct performance was the excess pore water pressure. The excess pore water pressuretime history curves are plotted in Figure 4 . The maximum excess pore pressure near the surface of the ground was approximately $8.8 \mathrm{kPa}$ based on the crust composition foundation and this value was recorded at the end of the second phase of construction. The maximum excessive pore pressure in the clay was not high enough, for a large portion of the embankment load was transferred to the piles as a result of (1) soil arching within filling layers, (2) shear stress developing in the pile-soil interface, and (3) dissipation of generated excessive pore pressures during the construction [9].

In addition, the stress was diffused owing to the high elastic modulus of the crust [26]. The comparison between the measured and computed excess pore water pressure using the finite-element model at the bottom of the crust is 


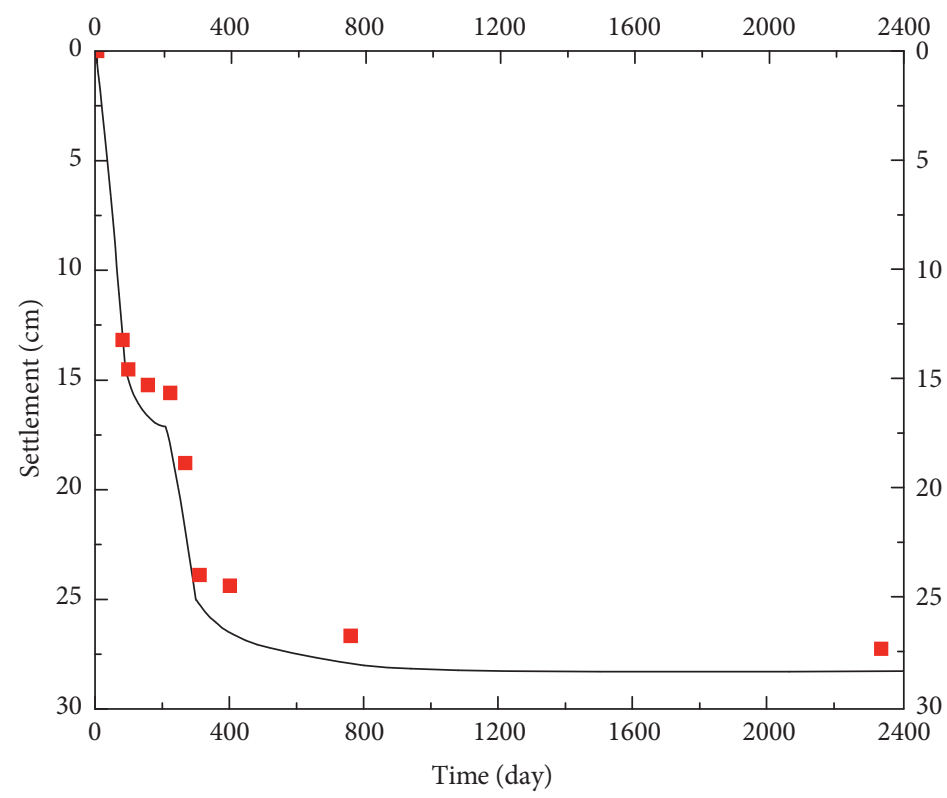

- Measured settlement Computed settlement

FIgURE 3: Measured and computed settlement at the base of the embankment.

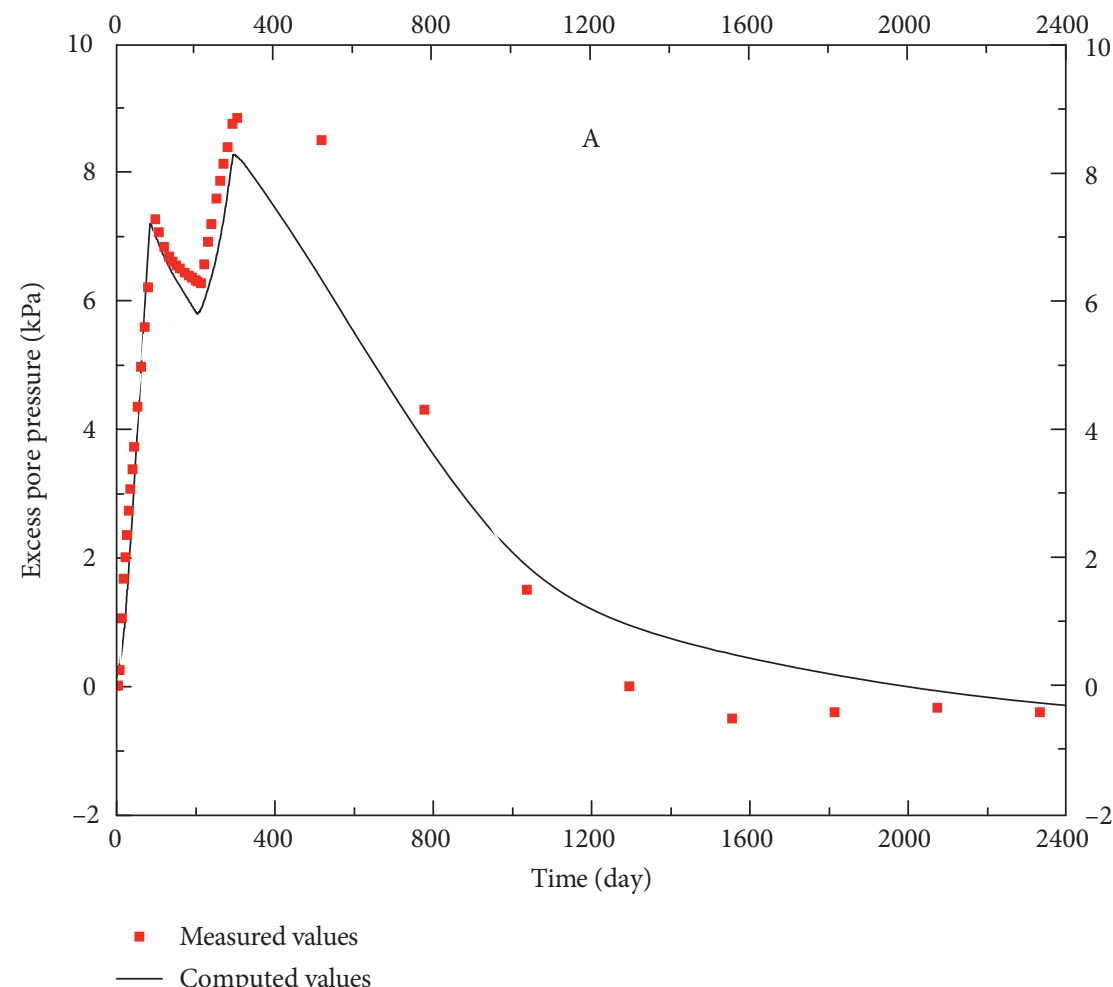

Figure 4: Measured and computed excess pore pressure at the base of the crust.

shown in Figure 4. The computed maximum excess pore pressure was approximately $8.4 \mathrm{kPa}$ and the dissipation rate of the excess pore water pressure agreed well with the experimental values. The finite-element model demonstrated the influence of the key factors on the excess pore water pressure.

The stress of soil in the crust composite foundation was analyzed by the pore water pressure. The pile that pierced the 
crust was set at the contact position between pile and crust owing to the large difference in modulus between the crust and the rigid pile. The shear failure of crust occurred when the top stress of the pile reached the shear failure stress of the crust oweing to the thickness of pile piercing the crust increased. So, the thickness of pile that pierced the crust is important to analyze in order to avoid the failure of the foundation.

Based on the analysis of the thickness of pile that pierced the crust, it is found that the thickness was related to the pile, soil, and crust, as well as to the diameter and replacement rate of piles. The thickness was analyzed based on the theory of hole expansion in this paper. Firstly, it was assumed that (1) the soil between piles and the crust was ideal elastic-plastic models. The Mohr-Coulomb failure criteria or Tresca failure criteria were suggested to describe the materials; (2) the shape of the pile at the top was hemispherical, the internal pressure was assumed to be uniform, and the internal pressures expand to the surrounding crust, which was the initial state. According to the stress of foundation changing,, the expansion pressure increased as the stress of the pile $p_{p}(0)$ at the top increased, and the soil around the spherical hole gradually entered the plastic state from the elastic state. According to the stress development process, see the following.

When $P_{\mathrm{p}}(0) \leq P_{\mathrm{s}}$, the soil around the spherical hole was in elastic state:

$$
S_{T}=\frac{r_{0}(1+v) p_{p}(0)}{E_{C}} .
$$

When $P_{\mathrm{p}}(0)>P_{\mathrm{s}}$, the soil around the spherical hole was in plastic state:

$$
S_{T}=\frac{r_{0}}{E_{c}}\left[3(1-v)\left(\frac{r_{p}}{r_{0}}\right)^{3} p_{e}-2(1-2 v) p_{p}(0)\right],
$$

where $p_{e}$ is the ultimate expansion stress, $p_{e}=4\left(c \cos \varphi+\sigma_{0} \sin \varphi\right) / 3-\sin \varphi$, and $p_{p}(0)$ is the stress of the pile at the top:

$$
\begin{aligned}
r_{p} & =\left(\frac{p_{p}(0)+\sigma_{0}+c \cot \varphi}{p_{e}+\sigma_{0}+c \cot \varphi}\right)^{t} r_{e}, \\
t & =\frac{4 \sin \varphi}{1+\sin \varphi},
\end{aligned}
$$

where $\sigma_{0}$ is the initial stress and $c, \varphi$ are cohesion and friction angle of the crust. $S_{T}$ is the thickness of the pile that pierced the crust.

The formula can be simplified as follows:

$$
S_{T}=a-b p_{p}(0)
$$

where

$a=3(1-v)\left(r_{p} / r_{o}\right)^{3} p_{e}\left(r_{0} / E_{c}\right), b=2(1-2 v)\left(r_{0} / E_{c}\right), r_{0} \quad$ is equivalent diameter, $r_{0}=\sqrt{s^{2} / \pi}, s$ is the distance of pile, and $r_{p}$ is the diameter of the pile.
According to equation (7), when the pile type was determined, the thickness of the pile that pierced the crust was related to the elastic modulus of the crust, the distance of pile, and the stress of pile at the top.

4.1.3. Tension Stress of the Crust. The cracking damage of the crust in the crust composite foundation was likely to occur. To study the cracking destruction of the crust, a strain gauge was posted in the zone prone to cracking damage. Additionally, as the artificial crust stress changed over time, the time of the maximum tensile stress should be known. The tensile stress-time curves are shown in Figure 5, which indicates that the largest tensile stress occurs in the middle of the crust [16]. The data presented in Figure 5 also show that the tensile stress increases with the load but decreases at equal loading because of the consolidation of the subsoil. Accordingly, the maximum tensile stress occurred at the end of the construction. Thus, the cracking damage of the crust occurred during the loading period.

Based on the centrifuge model test, the largest tensile stress occurred in the middle of the crust and the characteristics of a similar plate were taken to depend on the tensile stress changing, as well as on the maximum tensile stress occurring at the end of the construction. So, the crust cracks because of the bending in the transverse direction, leading to horizontal tensile stress and a corresponding vertical cracking.

The stress of the artificial crust layer cannot be directly determined by the 2D FE model. A theoretical analysis of elastic mechanics was carried out. A plane-strain model was used to analyze the relative deformation. The origin point was set on the left side of the crust layer and the orientation to the right was equal to the positive direction of the $x$-axis; the downward direction was equal to the positive direction of the $z$-axis. The width of the stabilization situation equaled $\mathrm{B}$ at this time. According to the symmetry of stress, the boundary conditions were set as a free boundary; therefore, it was assumed that the deformation equation of the foundation was as follows:

$$
w(x)=\sum_{i=1,3,5}^{\infty} \frac{A_{i} \sin i \pi x}{B}+B_{i}
$$

where $A_{i}$ is the relative deformation of the crust layer and the deformation of the foundation is $A_{i}+B_{i}$.

According to the theory of elastic mechanics, the stress of the artificial crust layer is expressed as follows:

$$
M_{x}=-D\left(\frac{\partial^{2} w}{\partial z^{2}}+\mu \frac{\partial^{2} w}{\partial x^{2}}\right)
$$

The maximum tension stress is as follows:

$$
\sigma_{x}=\frac{E}{1-\mu^{2}}\left(\frac{\partial^{2} w}{\partial z^{2}}+\mu \frac{\partial^{2} w}{\partial x^{2}}\right) h \Rightarrow \sigma_{x \max }=\sum_{i=1,3}^{\infty} \frac{E H}{2\left(1-\mu^{2}\right)} \mu\left(\frac{i \pi}{B}\right)^{2} A_{i},
$$




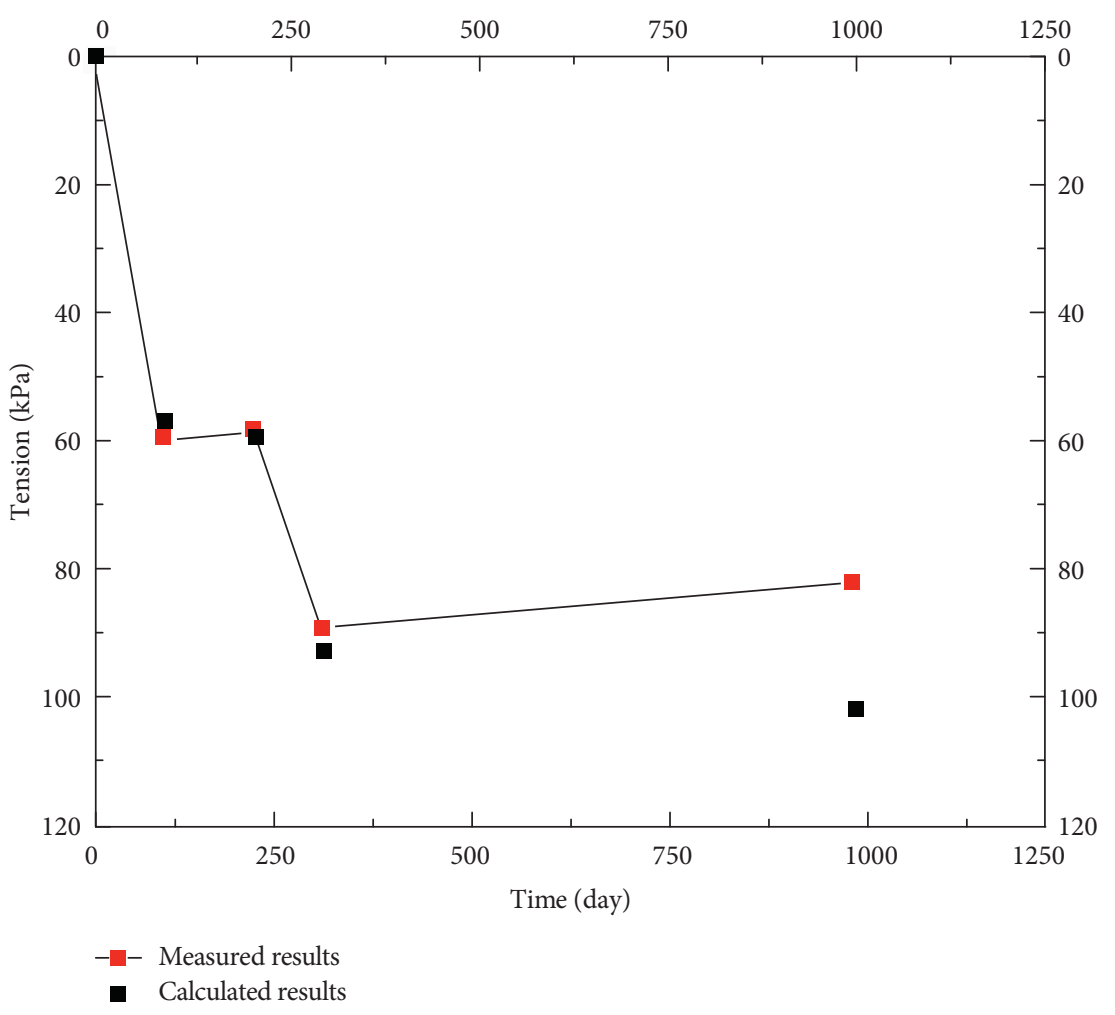

FIGURE 5: Measured and calculated tensile stress at the base of the crust.

where $D=E H^{3} / 12\left(1-v^{2}\right)$ is the bending rigidity of the crust layer (in $\mathrm{kN} \cdot \mathrm{m}$ ), $E$ is the modulus of compression, $\mu$ is the Poisson ratio, and $h$ is the distance of the base from the neutral axis. $H$ is the thickness of the crust layer.

The stress of the artificial crust layer in equation (10) showed that the stress was related to the elastic modulus, the thickness, the width of the crust, and the deflection difference. Based on the above factors, the deflection difference of the artificial crust was the key factor.

The deflection difference of the artificial crust was confirmed by the 2D FE model and the tension was calculated by equation (10). Subsequently, the calculated tension was compared with the measured tension, as shown in Figure 5. At the end of the construction, the measured tension value was $93 \mathrm{kPa}$ and the calculated value was $96.6 \mathrm{kPa}$, indicating that the calculated tension agreed well with the experimental value. Moreover, the measured results showed that the tensile stress decreased at equal loading because of the consolidation of the subsoil and the final tensile stress was $85.6 \mathrm{kPa}$. However, the calculated tensile stress was $106 \mathrm{kPa}$, which was different compared to the measured tensile stress. This can be explained because the foundation stress was changed owing to the piles being modeled as continuous walls in the 2D FE model. Based on these results, the calculated tension equation and $2 \mathrm{D} \mathrm{FE}$ model can be applied to the analysis of the tensile stress of the crust.

4.2. Discussion. In the artificial crust composition foundation, the pile spacing and the thickness and strength of the artificial crust are the main design factors when the pile size was determined. In addition, based on above analysis and the summarized former research production [4, 35-37], the strength of the crust obtained from unconfined compression strength in the laboratory is related to the elastic modulus in the finite-element model. In this study, the values of the influence factors have been listed in Table 2. As mentioned previously, one parameter was changed from the baseline case at one time to confirm the effect of that specific factor. The ranges of all the factors cover the typical ranges for practical applications.

\subsubsection{Influence of Pile Spacing}

(1) Settlement. Pile spacing was an important design parameter. Once the size of the pile was decided, the spacing pile was directly related to the area replacement ratio of the piles (e.g., a larger pile spacing results in a smaller area replacement ratio). In addition, a large pile spacing can also cause tension cracks in middle of the crust. Figure 6 shows that the pile spacing has a significant influence on the maximum settlement. An increase in the pile spacing in all of these values as the column spacing extended from 2.0 to $3.0 \mathrm{~m}$. However, within the range of the pile space, it had a limited influence on the maximum settlement.

An increase in the pile spacing from 3.0 to $3.5 \mathrm{~m}$ only resulted in less than $1 \mathrm{~mm}$ increase in the maximum settlement. The major reason for this phenomenon may be because the area replacement ratio of the piles was large and a stable soil arch was formed. Consequently, Figure 6 
TABLE 2: Values of influence factors used.

Parameter

Thickness of the crust (m)

Elastic modulus of the crust (MPa)

Pile spacing $(\mathrm{m})$
Range of value

$1.0,1.5,1.7,2.0$

$100,200,300$

$2.0,2.5,3.0,3.5$

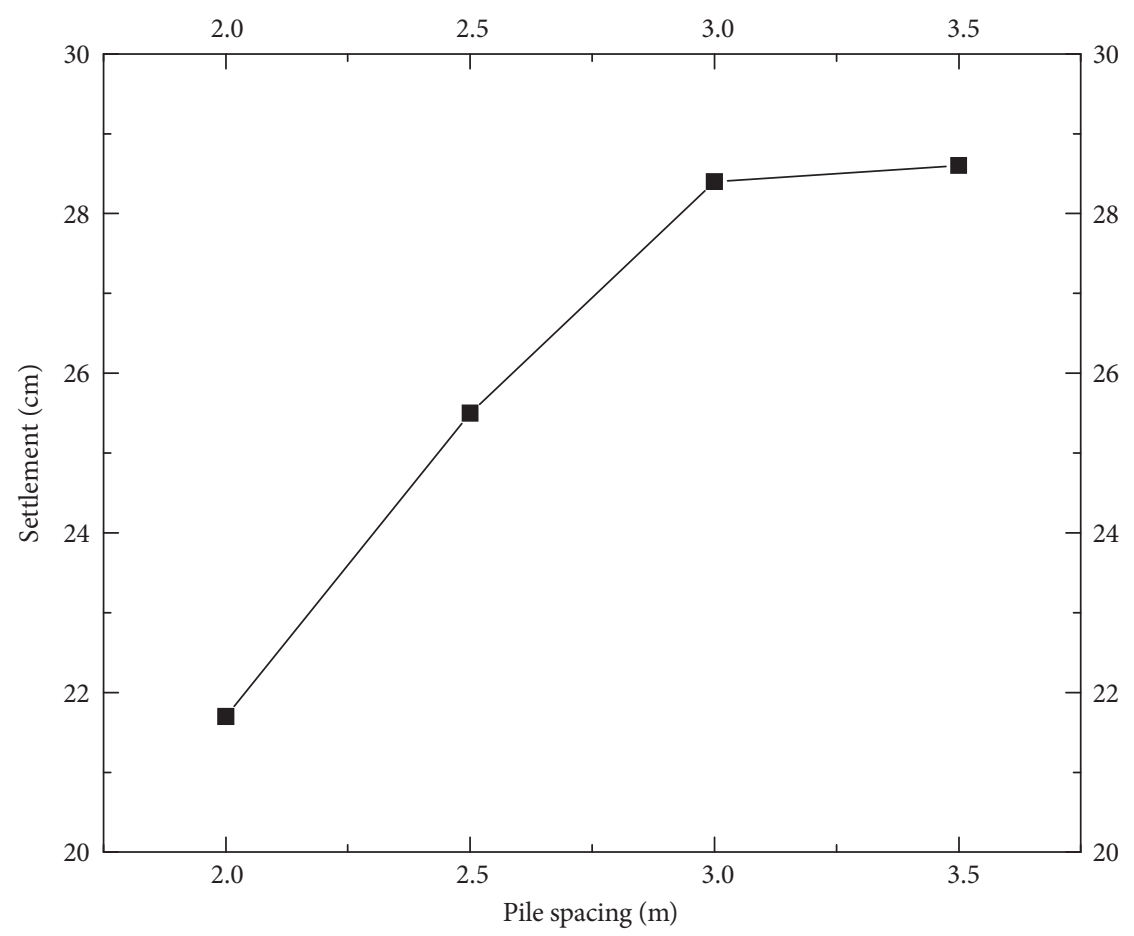

Figure 6: Maximum settlement versus pile spacing.

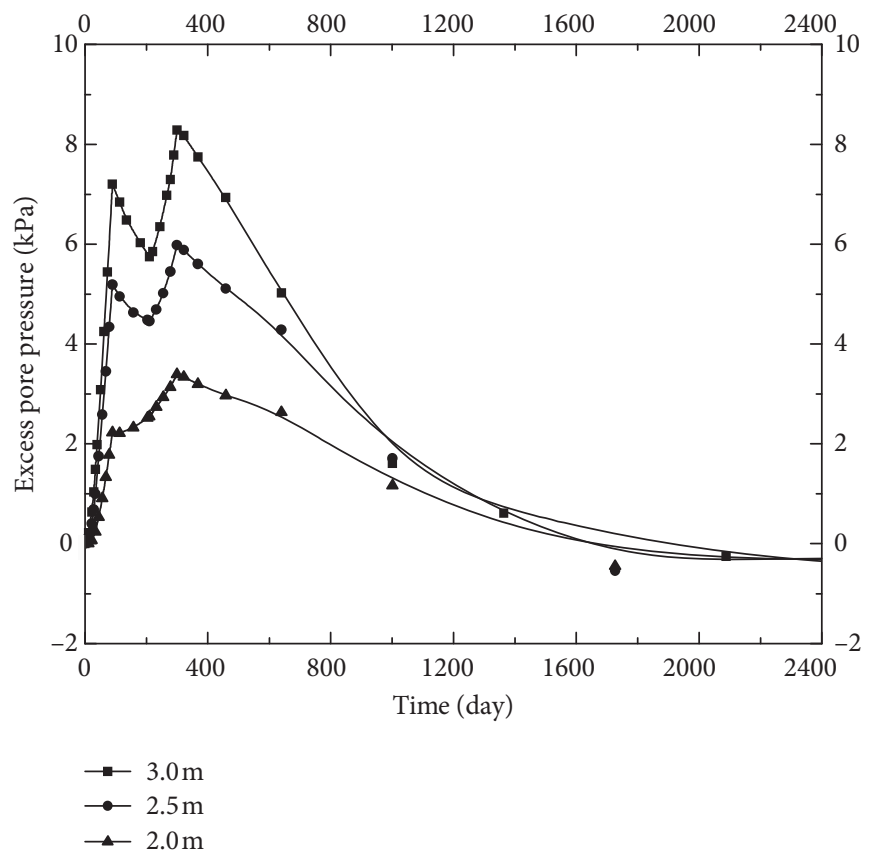

FIGURE 7: Excess pore pressure versus time with different pile spacing. 
indicates that the maximum settlement is the main scope of change and increases by about $31 \%$ as the pile spacing increases from 2.0 to $3.0 \mathrm{~m}$.

(2) Excess Pore Water Pressure. The influence of the pile spacing on the excess pore pressure is presented in Figure 7. An increase in the pile spacing resulted in a great change in excess pore pressure as the pile spacing increased from 2.0 to $3.0 \mathrm{~m}$. It was shown that the excess pore pressure increased gradually with an increase in the pile spacing, which indicates that the stress of the foundation increased and that less load was transferred to the piles. According to the analysis of the excess pore pressure dissipation rate, the speed of the pore pressure dissipation was faster as the pile spacing increased. As the effective stress in the soil increases with extending pile spacing, this has attributed to the fact that the soil tends to settle more than the piles. A portion of the load may be transferred to the piles on shear stresses within the embankment due to the relative movement between the soft soil and the piles.

As a result, the excess pore water pressure in the soft soil dissipated much faster. In addition, shearing failure of the artificial crust may happen at the top of the pile owing to the different properties of the crust and the piles. The shearing failure was related to the stress at the top of the pile. So, according to the analysis of the stress of the pile, as the pile spacing increased, the probability of shearing failure is reduced with an increase in the pile spacing. The thickness of the pile that pierced the crust is reduced with an increase in the pile spacing by equation (7), the same as the results of the numerical simulation method.

(3) Tension Stress of the Crust. The stress of the artificial crust layer described in equation (10) indicated that the deflection difference of the artificial crust was a key factor. The deflection difference of the artificial crust increased with an increase in the pile spacing at the same loading. Figure 8 shows that the deflection difference of the artificial crust increased from $14.39 \mathrm{~cm}$ to $20.69 \mathrm{~cm}$ as the pile spacing increased from 2.0 to $3.0 \mathrm{~m}$ and the tensile stress increased from 73.7 to $106 \mathrm{kPa}$, as defined in equation (10). The probability of tensile cracks is reduced with a decrease in the pile spacing. The pile spacing had a considerable influence on the type of the artificial crust damage and was a key factor in the engineering design.

It is found that the pile spacing has a great change in the type of failure of artificial crust with the impact of pile spacing on excess pore water pressure and tensile stress of artificial crust. The probability of shearing failure is reduced with an increase in the pile spacing. However, the probability of tensile cracks is increased. So, it is important to choose the appropriate pile spacing, which avoids the tensile crack or shearing failure of the crust.

\subsubsection{Influence of the Thickness of the Crust}

(1) Settlement. The thickness of crust was a key design factor. the stress concentration occurring at the crust combined with the rigid pile in the artificial crust composition foundation resulted in the rigid pile piercing the crust. When the ultimate stress was reached, a cracking failure of the crust occurred and the diffusion of the stress disappeared. Based on these conditions, the crust has to possess sufficient thickness. On the other hand, the stress on the top of the pile increased with the thickness, increasing the cost of construction. Therefore, the appropriate thickness of the crust has to be determined. As the thickness increased from 1.0 to $2.0 \mathrm{~m}$, the maximum settlement changed significantly as shown in Figure 9. The maximum settlement decreased by about $4 \%$ with an increase in the thickness from 1.0 to $1.5 \mathrm{~m}$. However, the maximum settlement decreased by about $9 \%$ as the thickness increased from 1.5 to $2.0 \mathrm{~m}$. Compared with the change in the ratio of the settlement, the thickness had relatively little influence on the maximum settlement.

(2) Excess Pore Water Pressure. Figure 10 shows that the excess pore pressure decreased with the increase in the thickness of the crust. This indicates that the stress of the foundation was diffused quickly with the increase in the thickness of the artificial crust and as a larger amount of the load was transferred to the piles, the rigid pile became prone to piercing the crust. The increase in the thickness of the crust accelerated the dissipation of the excess pore water pressure owing to the enclosed effect of the crust. The computed maximum excess pore pressure was approximately $9.4 \mathrm{kPa}$ with a $1.0 \mathrm{~m}$ thick crust and $8.1 \mathrm{kPa}$ with a 2.0 thick crust, a reduction of about $14 \%$. This indicates that the diffusion effect of the stress was clear with the increase in the crust thickness in the foundation. On the basis of the stress balance principle, the load on the top of the pile increased with the increase in the thickness of the crust; therefore, the thickness of the pile that pierced the crust increased.

(3) Tension Stress of the Crust. The deflection difference of the artificial crust decreased with an increase in the thickness at the same loading. Figure 11 shows that the deflection difference of the artificial crust decreased from 20.30 to $18.83 \mathrm{~cm}$ as the thickness increased from 1.0 to $2.0 \mathrm{~m}$; the deflection difference of the artificial crust decreased by about $26 \%$. However, the tensile stress increased from 76.1 to $113.3 \mathrm{kPa}$ (as described in equation (10)), an increase of 1.5 times. The tensile stress was related not only to the deflection difference but also to the thickness. Based on the above research, it is found that the thickness of crust multiplying the deflection difference has influence on the tensile stress. So, the tensile stress increased with the thickness increased.

\subsubsection{Influence of Elastic Modulus of Crust}

(1) Settlement. In this study, the elastic modulus of the crust was correlated to the undrained shear strength [4, 35-37]. When the modulus of the crust changed, the cohesion was adjusted correspondingly to maintain the same relationship between the modulus and the cohesion. Therefore, the modulus of the crust was an indicator of both stiffness and strength. It was expected that the stiffness of the crust plays 


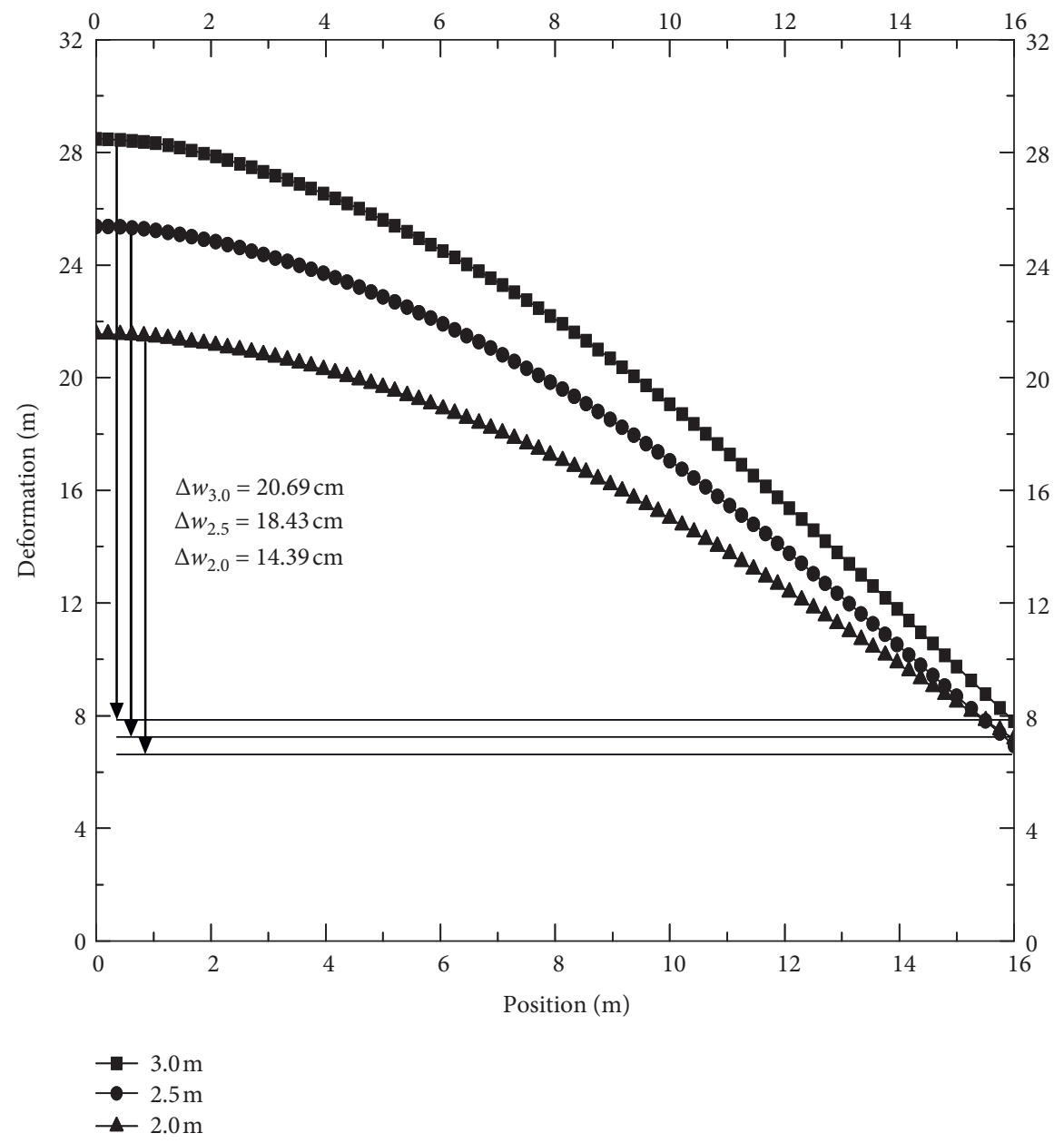

FIgURE 8: Deformation versus time with different pile spacing.

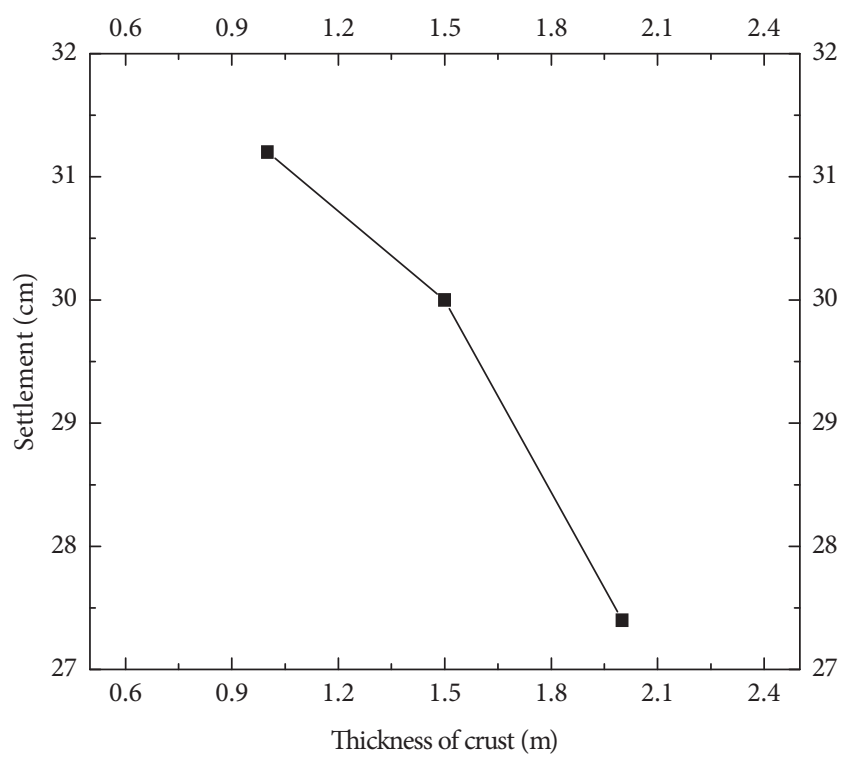

FIGURE 9: Settlement versus thickness of crust.

an important role in the transmitting of the embankment. The effect of the elastic modulus of the crust on the maximum settlement is presented in Figure 12.
It shows that the modulus had a great effect on the maximum settlement and that the maximum settlement changed linearly with a change in the elastic modulus of the crust. Therefore, the elastic modulus of the crust had a significant influence on the maximum settlement, it also showed that the strength of the crust had a great influence on the settlement of the foundation.

(2) Excess Pore Water Pressure. Figure 13 shows that a higher degree of consolidation resulted from the higher elastic modulus of the crust. The accelerated dissipation of the excessive pore water pressure was attributed to the transfer from the soil to the piles.

At the same position, the stress was diffused quickly with an increase in the crust's modulus. With the increase in the modulus, the stress of the foundation soil was reduced, resulting in a transfer of a larger load from the soil to the piles; this was attributed to the characteristics of the plate with the increase in the stiffness of the artificial crust.

However, the thickness of the pile that pierced the crust was reduced due to the increase in the modulus as the crust's thickness increased, which is the same as the results of the calculation by equation (7). 


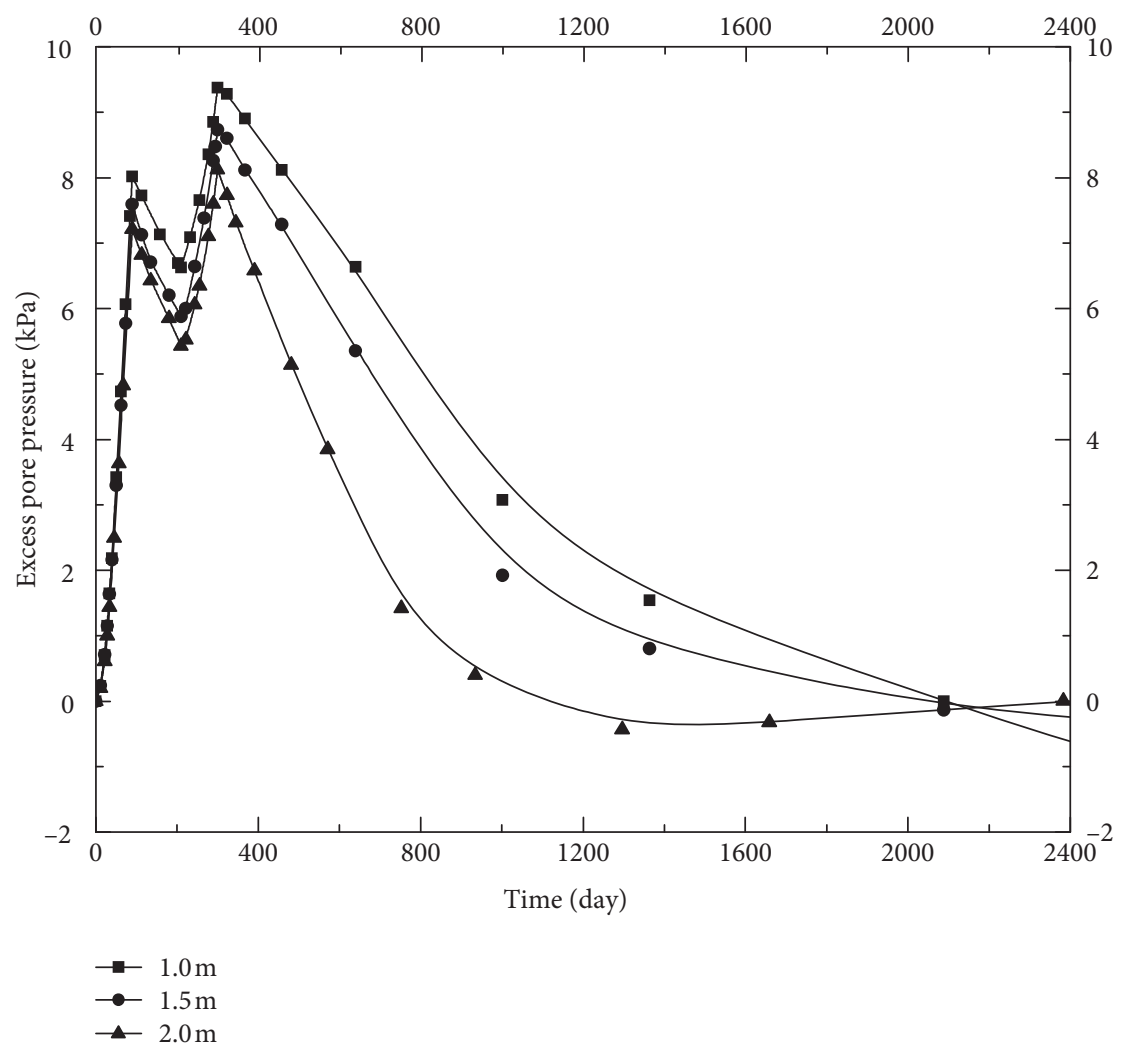

Figure 10: Excess pore pressure versus time with different thickness of crust.

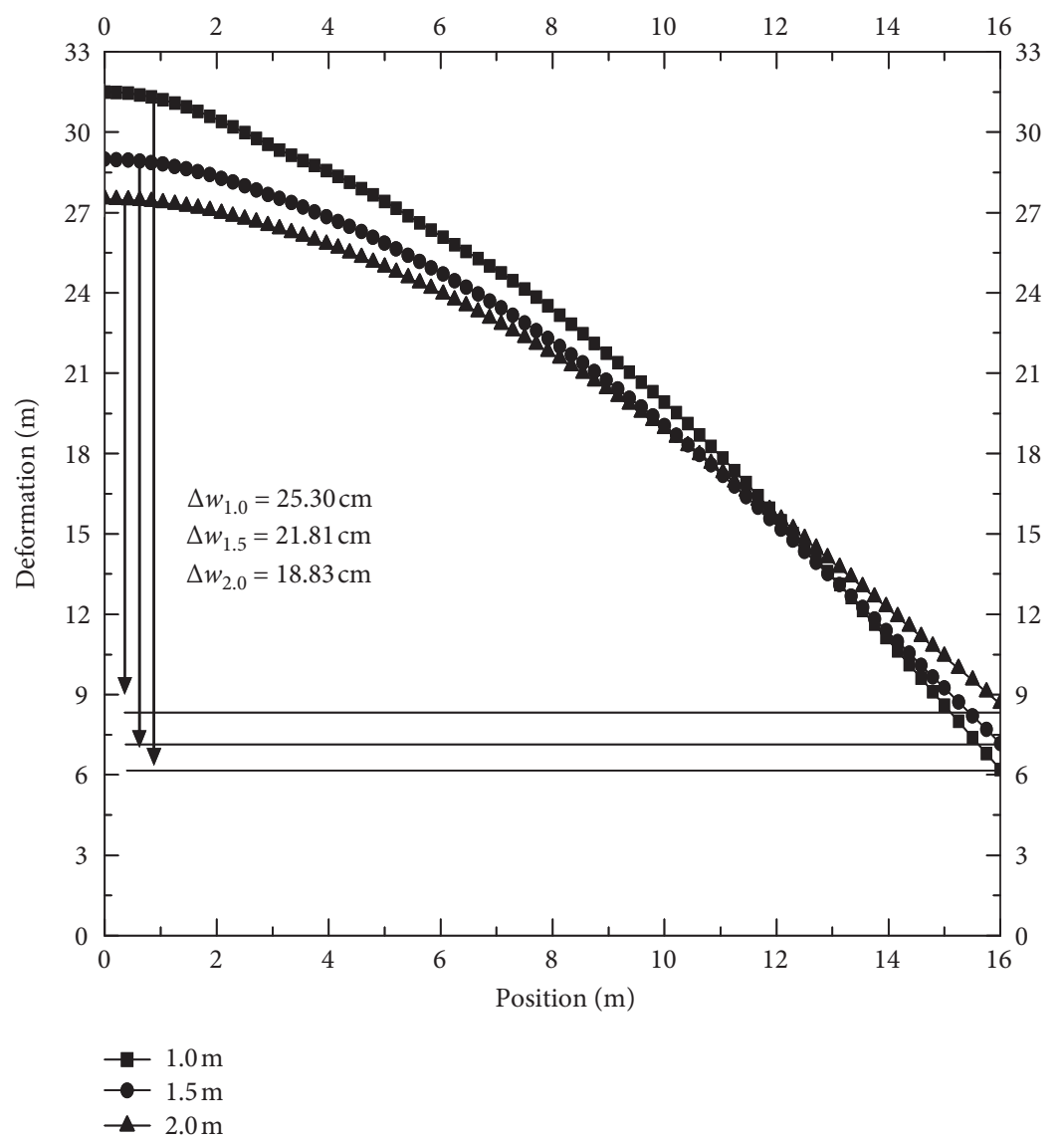

FIGURE 11: Deformation versus time with different thicknesses of crust. 


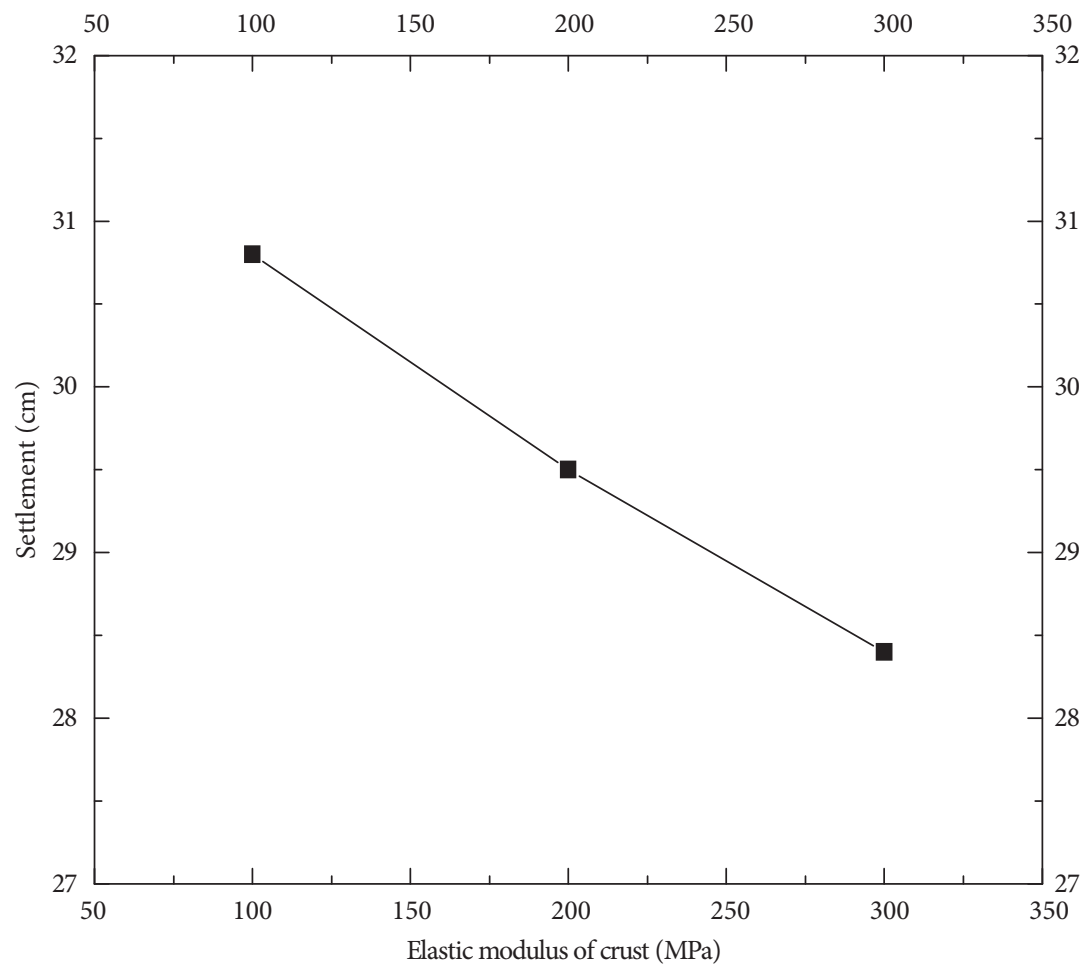

Figure 12: Settlement versus the elastic modulus of crust.

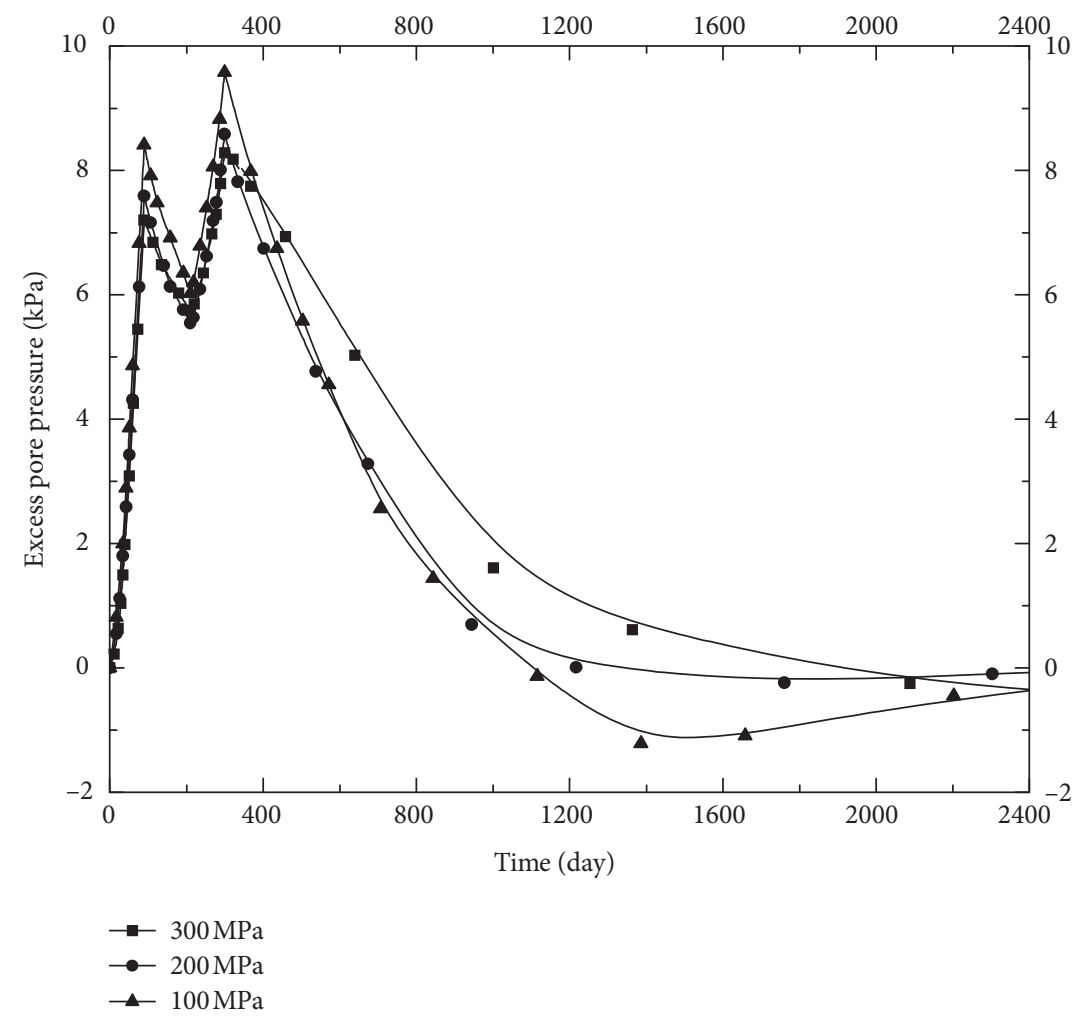

FIGURE 13: Excess pore pressure versus time with different elastic modulus of crust. 


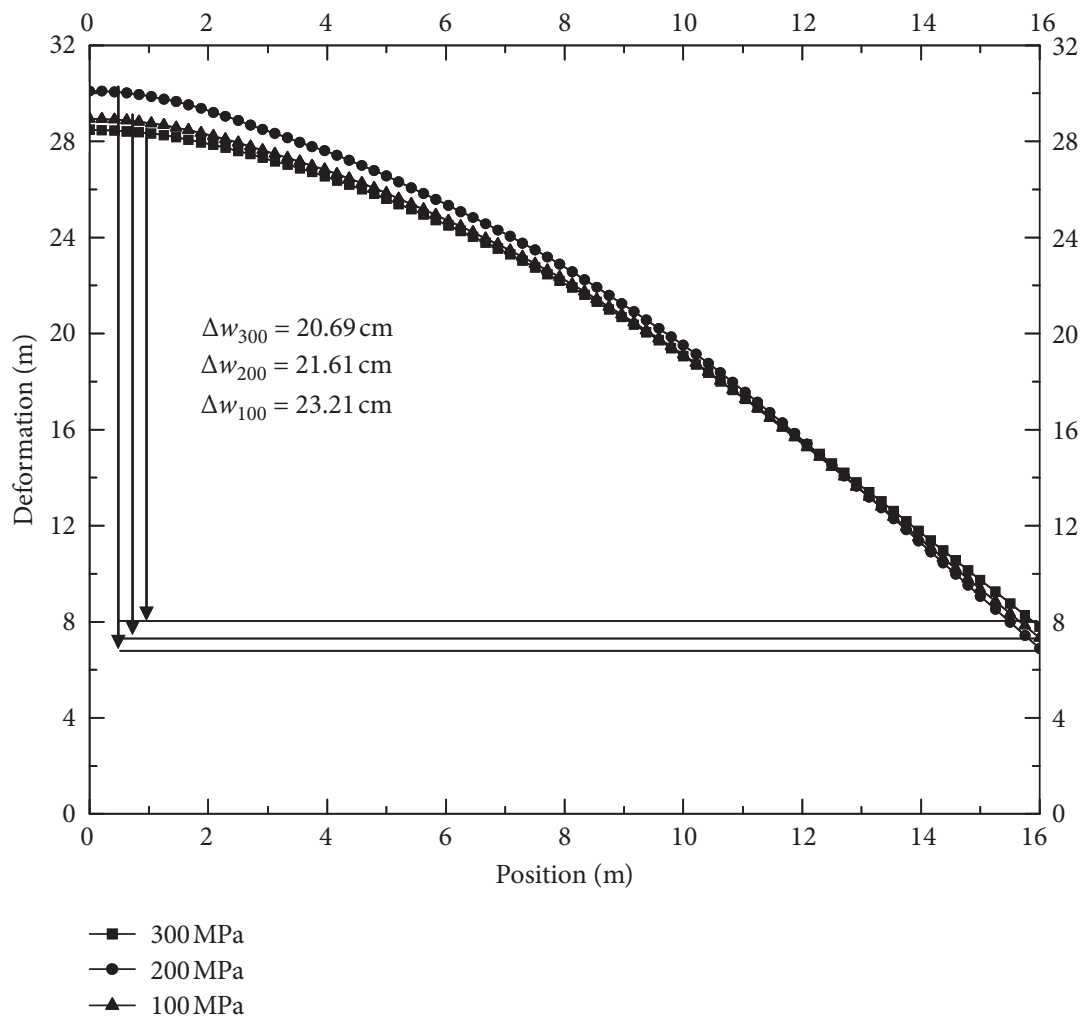

FIGURE 14: Deformation versus time with different elastic modulus of crust.

(3) Tension Stress of the Crust. Figure 14 shows that the deflection difference of the artificial crust decreased from 23.21 to $20.69 \mathrm{~cm}$ as the elastic modulus of the artificial crust increased from 100 to $300 \mathrm{MPa}$; the deflection difference of the artificial crust decreased by about $11 \%$. However, the tensile stress of the artificial crust increased from 39.64 to $106 \mathrm{kPa}$ (as described in equation (10)), an increase of 2.7 times. The elastic modulus had a significant influence on the tensile stress of the artificial crust but a small influence on the deflection difference of the artificial crust.

Based on the above research, it is found that the elastic modulus of the artificial crust had a little effect on the settlement and stress of the foundation but had a greater impact on the tensile stress of the artificial crust.

\section{Conclusions}

A centrifuge test and two-dimensional coupled-consolidation finite-element analyses were conducted to simulate the construction of an embankment for stabilization combined with rigid piles. Based on the two-dimensional coupled-consolidation finite-element models, the impact of several key factors including pile spacing, as well as the thickness and strength of the crust on the maximum long-term settlement, excess pore water, and tensile stress was discussed. Based on the discussions, the following conclusions can be drawn.

A comparison of the results of the centrifuge test and the finite-element analyses indicates that the measured settlement, excess pore water, and tensile stress of the centrifuge test are in good agreement with the calculated results; therefore, two- dimensional coupled-consolidation finite-element analyses were conducted to simulate the construction of an embankment for stabilization combined with rigid piles.

The pile spacing has a considerable effect on the settlement, pore water pressure, and tensile stress in the twodimensional coupled-consolidation finite-element models. With an increase in the pile spacing, the tensile stress of the crust increased, which resulted in an increasing potential for the tensile failure of the crust; however, the thickness of the pile that pierced the crust is reduced, so the potential of a punching failure of the crust can be reduced. The pile spacing is an important design parameter in the artificial crust composite foundation.

The thickness and the elastic modulus of the crust have a little effect on the settlement and the stress of the foundation in the two-dimensional coupled-consolidation finite-element models. Based on the above research, it is found that the increasing thickness and elastic modulus of the crust have a greater impact on the tensile stress, and the thickness of the pile that pierced the crust was reduced as the increasing modulus and thickness of the crust.

\section{Data Availability}

The data used to support the findings of this study are available from the corresponding author upon request.

\section{Conflicts of Interest}

The authors declare no conflicts of interest. 


\section{Acknowledgments}

This project was supported by the Natural Science Foundation of Shandong Province under Grants ZR2017BD037 and ZR2019PEE044; the Post-Doc Creative Funding in Shandong Province under Grant 201703023; and Key Laboratory of Ministry of Education for Geomechanics and Embankment Engineering, Hohai University, under Grant 2019001.

\section{References}

[1] L. I. Lian-xiang, J. I. Xiang-kai, L. I. U. Jia-dian et al., "Centrifugal model tests on lateral mechanical properties of composite foundation under different additional loads," Chinese Journal of Geotechnical Engineering, vol. 41, no. S1, pp. 153-156, 2019.

[2] J. Yang, M. Yang, and R. Luo, "Dynamic centrifuge model test of composite foundation with rigid pile in soft clay," Chinese Journal of Underground Space and Engineering, vol. 15, no. 02, pp. 381-401, 2019.

[3] Q. J. Yang, Y. F. Gao, D. Q. Kong et al., "Centrifuge modelling of lateral loading behaviour of a semi-rigid Mono-pile in soft clay," Marine Geotechnology, vol. 47, no. 3, pp. 1205-1216, 2019.

[4] G. M. Filz and M. P. Navin, "Stability of column-supported embankments," Rep. No. VTRC 06-CR13, Virginia Transportation Research Council, Charlottesville, VA, USA, 2006.

[5] J. Huang, J. Han, and S. Oztoprak, "Coupled mechanical and hydraulic modeling of geosynthetic-reinforced column-supported embankments," Journal of Geotechnical and Geoenvironmental Engineering, vol. 135, no. 8, pp. 1011-1021, 2009.

[6] J. L. Borges and D. O. Marques, "Geosynthetic-reinforced and jet grout column-supported embankments on soft soils: numerical analysis and parametric study," Computers and Geotechnics, vol. 38, no. 7, pp. 883-896, 2011.

[7] N. Yapage, S. Liyanapathirana, H. G. Poulos et al., "2D numerical modelling of geosynthetic reinforced embankments over deep cement mixing columns," in Anz 2012: Ground Engineering In A Changing World: Conference Proceedings: 11Th Australia-New Zealand Conference On Geomechanics, vol. 15-18, pp. 578-583, Melbourne, Australia, July 2012.

[8] Y. Jiang, J. Han, and G. Zheng, "Influence of column yielding on degree of consolidation of soft foundations improved by deep mixed columns," Geomechanics and Engineering, vol. 6, no. 2, pp. 173-194, 2014.

[9] M. E. Stewart and G. M. Filz, "Influence of clay compressibility on geosynthetic loads in bridging layers for columnsupported embankments," Geo-frontiers Congress, vol. 156, no. 130, pp. 1-14, 2005.

[10] P. Ariyarathne and D. S. Liyanapathirana, "Review of existing design methods for geosynthetic-reinforced pile-supported embankments," Soils and Foundations, vol. 55, no. 1, pp. 17-34, 2015.

[11] Y. Pan, Y. Liu, H. Xiao, F. H. Lee, and K. K. Phoon, "Effect of spatial variability on short- and long-term behaviour of axially-loaded cement-admixed marine clay column," Computers and Geotechnics, vol. 94, pp. 150-168, 2018.

[12] Y. Pan, Y. Liu, F. H. Lee, and K. K. Phoon, "Analysis of cement-treated soil slab for deep excavation support - a rational approach," Géotechnique, vol. 69, no. 10, pp. 888-905, 2019.
[13] Y. Pan, Y. Liu, A. Tyagi et al., "Model-independent strengthreduction factor for effect of spatial variability on tunnel with improved soil surrounds," Géotechnique, pp. 1-17, 2020.

[14] T. Namikawa and S. Mihira, "Elasto-plastic model for cementtreated sand," International Journal for Numerical and Analytical Methods in Geomechanics, vol. 31, no. 1, pp. 71-107, 2007.

[15] T. Namikawa and J. Koseki, "Effects of spatial correlation on the compression behavior of a cement-treated column," Journal of Geotechnical and Geoenvironmental Engineering, vol. 139, no. 8, pp. 1346-1359, 2013.

[16] A. Tyagi, Y. Liu, Y. T. Pan et al., "Stability of tunnels in cement-admixed soft soils with spatial variability," Journal of Geotechnical and Geoenvironmental Engineering, vol. 144, no. 12, Article ID 06018012, 2018.

[17] M. Arroyo, M. Ciantia, R. Castellanza, A. Gens, and R. Nova, "Simulation of cement-improved clay structures with a bonded elasto-plastic model: a practical approach," Computers and Geotechnics, vol. 45, pp. 140-150, 2012.

[18] M. Hyodo, Y. Wu, N. Aramaki, and Y. Nakata, "Undrained monotonic and cyclic shear response and particle crushing of silica sand at low and high pressures," Canadian Geotechnical Journal, vol. 54, no. 2, pp. 207-218, 2017.

[19] Y. Wu, N. Li, M. Hyodo, M. Gu, J. Cui, and B. F. Spencer, "Modeling the mechanical response of gas hydrate reservoirs in triaxial stress space," International Journal of Hydrogen Energy, vol. 44, no. 48, pp. 26698-26710, 2019.

[20] Y. Wu, H. Yamamoto, J. Cui et al., "Influence of load mode on particle crushing characteristics of silica sand at high stresses," International Journal of Geomechanics-ASCE, vol. 20, no. 3, Article ID 04019194, 2020.

[21] S. Wang, X. Lei, Q. Meng, J. Xu, M. Wang, and W. Guo, "Model tests of single pile vertical cyclic loading in calcareous sand," Marine Georesources \& Geotechnology, pp. 1-12, 2020.

[22] J. Huang and J. Han, "Two-dimensional parametric study of geosynthetic-reinforced column-supported embankments by coupled hydraulic and mechanical modeling," Computers and Geotechnics, vol. 37, no. 5, pp. 638-648, 2010.

[23] J.-C. Chai, S. Shrestha, T. Hino, W.-Q. Ding, Y. Kamo, and J. Carter, "2D and 3D analyses of an embankment on clay improved by soil-cement columns," Computers and Geotechnics, vol. 68, pp. 28-37, 2015.

[24] N. Jelisic and M. Leppänen, "Mass stabilization of organic soils and soft clay," in Proceedings of the 3th International Conference on Grouting and Ground Treatment, pp. 552-561, New Orleans, LA, USA, February 2003.

[25] R. Ishikura, H. Ochiai, N. Yasufuku, and K. Omine, "Estimation of the settlement of improved ground with floatingtype cement-treated columns," in Proceedings of the 4th International Conference on Soft Soil Engineering - Soft Soil Engineering, pp. 625-635, Vancouver, BC, Canada, October 2006.

[26] R. Ishikura, N. Yasufuku, and M. J. Brown, “An estimation method for predicting final consolidation settlement of ground improved by floating soil cement columns," Soils and Foundations, vol. 56, no. 2, pp. 213-227, 2016.

[27] C. W. W. Ng, "The state-of-the-art centrifuge modelling of geotechnical problems at hkust," Journal of Zhejiang University Science A, vol. 15, no. 1, pp. 1-21, 2014.

[28] M. Y. Yao, S. H. Zhou, and Y. C. Li, "Boundary effect analysis of centrifuge test," Chinese Quarterly of Mechanics, vol. 25, no. 2, pp. 291-296, 2004, in Chinese.

[29] D. J. White, W. A. Take, and M. D. Bolton, "Soil deformation measurement using particle image velocimetry (PIV) and 
photogrammetry," Géotechnique, vol. 53, no. 7, pp. 619-631, 2003.

[30] Y. Wang, Y. Chen, Z. Hu, Q. Feng, and D. Kong, "Comparative analysis of load responses and deformation for crust composite foundation and pile-supported embankment," Sains Malaysiana, vol. 46, no. 11, pp. 2231-2239, 2017.

[31] Z. Hu, Y. Wang, Y. Chen et al., "Deformation and failure mechanism of rapid stabilization for dredger fill in road engineering," Arabian Journal of Geosciences, vol. 33, no. 6, p. $11,2020$.

[32] G. R. McDowell, O. Harireche, H. Konietzky, S. F. Brown, and N. H. Thom, "Discrete element modelling of geogrid-reinforced aggregates," Geotech Engineering, vol. 159, pp. 35-48, 2006.

[33] P. Ariyarathne, D. S. Liyanapathirana, and C. J. Leo, "Comparison of different two-dimensional idealizations for a geosynthetic-reinforced pile-supported embankment," International Journal of Geomechanics, vol. 13, no. 6, pp. 754$768,2013$.

[34] K. Chan and B. Poon"Designing stone columns using 2D FEA with equivalent strips"in Proceedings of International Conference on Ground Improvement and Ground Control, B. Indraratna, C. Rujikiatkamjorn, and J. Vinod, Eds., University Of Wollongong, Wollongong, Australia, pp. 609-620, January 2012.

[35] N. N. S. Yapage, D. S. Liyanapathirana, R. B. Kelly, H. G. Poulos, and C. J. Leo, "Numerical modeling of an embankment over soft ground improved with deep cement mixed columns: case history," Journal of Geotechnical \& Geoenvironmental Engineering, vol. 140, no. 11, pp. 1-10, 2014.

[36] D. A. Bruce, "An introduction to the deep mixing methods as used in geotechnical applications, volume 3: the verification and properties of treated ground," Rep. No. FHWA-RD-99167, Federal Highway Administration, Washington, DC, USA, 2001.

[37] A. Porbaha, S. Shibuya, and T. Kishida, "State of the art in deep mixing technology. Part III:geomaterial characterization," Proceedings of the Institution of Civil Engineers - Ground Improvement, vol. 4, no. 3, pp. 91-110, 2000.

[38] K.-H. Xie, M.-M. Lu, A.-F. Hu, and G.-H. Chen, “A general theoretical solution for the consolidation of a composite foundation," Computers and Geotechnics, vol. 36, no. 1-2, pp. 24-30, 2009. 